\title{
Referring Phrases with Deictic Indication and the Issue of Comprehensibility of Texts of Normative Acts: The Case of Polish Codes
}

\author{
Maciej Kłodawski ${ }^{1}$
}

Published online: 19 August 2020

(c) The Author(s) 2020

\begin{abstract}
The paper focuses on a specific type of referring legal provisions, in which the referring phrase contains a component that indicates the position of a certain fragment of the same text of a normative act by determining the position of that fragment in relation to the fragment in which the given referring phrase is located. Despite the fact that these referrals, called deictic, may be perceived as uncomplicated in structure and as functioning correctly in legal texts, many theoretical as well as practical problems arise during their drafting and legal interpretation. The article attempts to reveal, organize and name these problems basing on the conceptual grid formulated by Studnicki, Łachwa, Fall and Stabrawa as a universal, although not widely known outside Polish jurisprudence, tool for analysing and solving referring provisions as elements of various legal systems, especially continental ones. Texts of selected Polish Codes have been chosen as an illustrative material of deictic referrals which have been incorrectly formulated as leaving space for interpretative doubts in terms of place of indication (demonstratum) and place of reference (referent), which also causes a potential problem of the deferred ostension phenomenon noticed by Quine. The author argues that proper drafting of referring legal provisions with deictic indication requires that the legislator should have extensive pragmalinguistic knowledge and is an essential part of law-making oriented towards achieving comprehensibility of texts of normative acts, especially as important as Codes.
\end{abstract}

\section{Introduction}

Drafting of texts of normative acts is nowadays perceived not only as an activity ensuring intelligibility, precision and other attributes of those texts, which are valuable to the "human" interpreter, but also as an activity, which is important from the

Maciej Kłodawski

maciej.klodawski@usz.edu.pl

1 Institute of Legal Studies, University of Szczecin, Narutowicza 17a Street, 70-240 Szczecin, Poland 
point of view of the growing demand for the automation of processing of texts of normative acts, which is similar to interpretation. This is due to the fact that the ambition of the artificial intelligence and law (AI \& Law) trend is to achieve the highest possible level of formalization of legislation and its implementation into a logical program capable of deriving conclusions based on the relevant content of normative acts combined with specific facts [37: 409]. The development of the AI \& Law trend also positively affects the extension of knowledge about "classic" ways of creating legal regulations and their interpretation. This is particularly evident in the practices included in the aforementioned trend aimed at detecting the types of provisions in texts of normative acts, which can be-and more and more often already is-effectively supported by more or less automated tools, as shown in the available literature [8: 15]. These practices help to provide knowledge that allows describing the relations between regulations, including relations shaped by referring provisions contained in texts of normative acts.

However, not all relations between regulations created through referrals in the mentioned texts are equally easy to identify, and thus are not equally easy to understand. This is especially the case when the reference created by a referral from a provision to another provision is completely dependent on the context, and moreover, on certain editorial and interpretative directives belonging to legal discourse, but not incorporated for obvious reasons into the text of a given normative act. Such referrals include those which arise by incorporating in the text of the normative act a referring phrase with a deictic indication. This article is dedicated to them.

This study aims to achieve two goals. The first goal is to show, from the perspective of philosophy of language and pragmalinguistics, the role of deixis in referring provisions with a deictic indication. The discussion on the referring provisions with a deictic indication will be about creating technical relations between the cross-reference provisions [7: 295-296], which do not indicate the fragment of the text to which the referral is made, neither by the editorial and systematic units in which the provisions are included, nor by means of publication addresses of normative acts, nor by means of the content or generic characteristics of the provisions, and finally nor by expressions typically used to increase the consistency of the text, though which do not indicate any items in it (such as "however", "even" or "except in cases"), but do so by naming the position of this fragment in relation to the fragment in which the referring phrase is located. So far, no study has been presented in the literature that would be devoted entirely to the issue of deictic referrals in texts of normative acts, ${ }^{1}$ which leaves space that deserves to be filled in relation to the second purpose of the article.

The second goal is to use a conceptual grid developed by Studnicki et al. [30]used nominally to describe, typologize and enable the automation of solving referrals in texts of Polish normative acts - to show, organize and name theoretical and practical difficulties in drafting and interpreting referring provisions with deictic indication in texts of Polish normative acts. Since the structure of these texts has

\footnotetext{
${ }^{1}$ However, they were discussed to a relatively small extent in the following works: [33: 35ff.] and [6: 42 and 46].
} 
remained essentially unchanged since the work of the abovementioned authors, their comments remain valid. As such, they give hope for enriching the theoretical layer of ways to facilitate the creation and processing of texts not only of Polish normative acts, but also of those derived from many other legislative systems. The terminology presented by the indicated researchers is, as it will be shown further, universal enough to be used to analyse the content of the text of each normative act, which has a hierarchical structure.

The article consists of eight parts, including the introductory part marked as first. The second part of the article (2.) contains a reconstruction of the conceptual apparatus proposed by Studnicki, Łachwa, Fall and Stabrawa for the purpose of perceiving, ordering and describing components of referring phrases with deictic indication appearing in texts of normative acts. In the third part (3.), explanations of deixis borrowed from the philosophy of language and linguistics are presented, including conceptual relations in which deixis occurs in relation to anaphora, indexicality and demonstratives. They allow a better understanding of reasons why this seemingly simple phenomenon causes editorial and interpretation difficulties regarding referring provisions with deictic indication. The fourth part (4.) presents the state of research on the comprehensibility of texts of normative acts, including the limitations of computational methods in determining the comprehensibility of texts of normative acts. Part five (5.) discusses the impact of referrals in texts of normative acts on their comprehensibility. Part six (6.) presents a justification for choosing Codes as a resource of examples illustrating problems with the creation and interpretation of deictic referrals. Part seven (7.) presents an analysis of examples of referrals with deictic indication taken from texts of selected Polish Codes, which gives an overview of the necessary requirements for the successful interpretation of the so-called deferred ostension phenomenon and the importance of preserving the theoretical and legal uniformity of the conceptual grid in the course of drafting referring provisions containing phrases with deictic indication. Part eight (8.) presents a summary, including some prospective comments.

\section{The Structure of Referring Phrases in Texts of Normative Acts and the Associated Conceptual Grid}

In the text of a normative act, the referring provision is the provision containing the referring phrase. The latter is understood as a linguistic phrase referring to the content expressed in other fragments of a given text of a normative act or in texts of other normative acts in such a way that it is not possible to interpret fragments containing these phrases without taking into account the said content [30: 15]. ${ }^{2}$ A referring provision understood in this way expresses a systemic reference, i.e. only to elements of the legal system [30: 15, footnote 1 and literature cited there], and this will

\footnotetext{
2 The definition of the referring phrase presented in the aforementioned work has been modified for the purpose of maintaining terminological uniformity - the authors of the source work use the term "legal texts", while in this article the term "texts of normative acts" is used.
} 
be the object of further analysis. Provisions referring outside the system, i.e. to other normative systems or their individual components, as well as to some assessments and values, are outside the scope of interest of this study. Including such provisions to this discussion would cause the need to significantly broaden the reasoning, inter alia with comments on the comprehensibility of texts expressing extra-legal assessments and values, or with a discussion on the structure and rules of the construction of texts forming normative systems other than law.

Characteristics of referring phrases appearing in referring provisions presented in the work of Studnicki, Łachwa, Fall and Stabrawa are extensive, satisfyingly explanatory and possible to be used to present the problem that is the main subject of the investigation presented in this article. Shedding some light on them, it should be pointed out that, according to these researchers, it is necessary to specify in the structure of a referring phrase two components which they call the functor of the referring phrase (FRP) and the argument of the referring phrase (ARP). FRP is a component signalling to the recipients of a text of a normative act that they have encountered a referring phrase, while ARP is a component that informs the recipients of the text of a normative act about what criteria should be used when searching in such a text for content to which the referring phrase refers [30: 38]. It is stipulated that both components of the referring phrase have their representation in the surface structure of such a phrase. Expressions representing FRP were referred to as the R-functor of the referring phrase (RFRP), and the expression representing ARP as the R-argument of referring phrase (RARP) [30: 39]. In this study, the term RFRP will be underlined, and RARP will appear in bold in order to make it easier to find them in the structure of a provision, because the order of RFRP and RARP is different in different provisions.

In the discussed work of Studnicki, Łachwa, Fall and Stabrawa, some of the above-mentioned components of referring phrases were further divided. When it comes to ARP, elements of lower-order were distinguished, which were called atoms, indicating that when it comes to an atom, it is such an element of an argument which determines that a given referring phrase has one of the semantic properties assigned by the authors to basic semantic properties [30: 40]. Moreover, two components of atoms were specified-standard of an atom and specification of an atom. Similarly, as in the case of FRP and ARP, individual atoms as well as their standards and specifications at the surface level of the text are represented respectively by expressions called R-atoms (RA), R-standards (RST) and R-specifications (RSP) [30: 41]. Both components of the atom must appear in the fragment of the text responsible for the reference expression. The explanation of what RST and RSP are, is clearly illustrated by the following example.

(1)

Art. $109^{2} \S 1$ sentence 2 of the Civil Code [22], hereinafter referred to as: "CC"

The provision of Art. 99 \$ 1 shall not apply.

As declared, RST and RSP are components of RARP. In example (1) RARP consists of two RAs. Therefore, since in each RA there is one RST and one RSP each, it is possible to find two RSTs ("Art." and "§") and two RSPs ("99" and " 1 ") in the 
analysed example. The first RA (for the purpose of this example it can be named $\mathrm{RA}_{\mathrm{a}}$ ) consists of RST $\mathrm{R}_{\mathrm{a}}$ "Art." and RSP “99". Similarly, $\mathrm{RA}_{\mathrm{b}}$ consists of $\mathrm{RST}_{\mathrm{b}}$ " $§$ " and $\mathrm{RSP}_{\mathrm{b}}$ " 1 ". Thus, it can be assumed that words (or their abbreviations) such as the nouns "Article", "Paragraph", "Sentence", "Chapter", "Act" etc. appear in the role of RST. The function of the RSP is often performed by numerals (also written with Arabic or Roman numerals), pronouns ("this"), adjectives ("preceding", "below-mentioned", "above-mentioned") or multi-word compounds semantically characterizing a given RST. The RSP class is much more extensive compared to the RST class and it does not seem reasonable to present all its elements.

It should be added to the above that the mentioned distinction between the semantic structure of a referring phrase and its surface structure, manifested by the introduction of R-expressions representing FRP, ARP, atoms, standards and specifications (RFRP, RARP, RA, RST and RSP, respectively) is justified by the lack of a full, i.e., present in each case, mutually unambiguous correspondence between these structures [30: 42]. There is no doubt that, for example, a referring phrase "listed in $\S 7$ " is the same at the level of surface structure on the grounds of two texts of different normative acts, despite completely different meanings. In turn, expressions "listed in $\S 7$ " and "listed in $\S 8$ " have the same semantic structure on the ground of a given normative act in which they appeared as referring phrases, but are characterized by absence of synonymity and a different surface structure.

The last concept that needs to be discussed before moving on to the main problem to which this study is devoted, is indication. According to Studnicki, Łachwa, Fall and Stabrawa, an indication is "(...) the way in which a given referring phrase indicates the content to which it refers" [30: 43]. The cited authors distinguish seven of those ways. Those are internally addressed, externally addressed, deictic, semantic, semaphoric, recurring and recurrent indications. A compound indication, which consists of combining the above-mentioned seven indications, bearing in mind that not all hypothetical combinations of indications are compatible [30: 156-161], is not a separate type of indication. A compound indication is an indication expressed with the use of ARP consisting of several atoms of different types [30: 151]. A given type of indication in a referring phrase means that such a phrase has one of the seven basic semantic properties. Example (1) represents an internally addressed indication and therefore the referring phrase "Art. $99 \S 1$ shall not apply" has only one basic semantic property as understood by Studnicki, Łachwa, Fall and Stabrawa. Referring phrases with a compound indication have as many basic semantic properties as there are types of indications found in them. Those, due to the desire to keep this article compact, will not be considered.

Among the identified types of indications it is the deictic indication which will be the subject of further investigation and analysis. Therefore, the focus will be on referrals containing " $(\ldots)$ such a referring phrase in which the R-argument contains a phrase indicating the position of a certain fragment of the same text by determining the position of that fragment in relation to the fragment in which the given referring phrase is located" [30: 48]. This kind of indication, as its name suggests, is associated with the phenomenon known as deixis, which-as will be shown in the next part of the article-is considered troublesome in language philosophy and pragmalinguistics. 


\section{Deixis and Deictic Expressions in Pragmalinguistics and Referrals with Deictic Indication in Texts of Normative Acts}

The source of problems with deixis involves the complexity of this phenomenon, which manifests itself in the need to determine what is indicated (demonstratum), and to what the reference is made by the deixis (referent) and whether these objects must always be identical. Difficulties in reflections on deixis are also caused by the types of deixes, distinguished on the basis of various criteria, as well as various relations and conceptual traditions in which deixis is sometimes settled and examined.

A report on the state of knowledge about deixis can begin by citing Yule's position, according to which deixis is simply a way of showing through language [38: 9]. In a more detailed description given by Levinson, deixis refers to a phenomenon in which understanding the meaning of certain words and expressions in an utterance requires contextual information. Words or phrases that require contextual information to convey meaning are deictic_as variables or placeholders for some particular entities given by the context [14: 54]. In other words, a deictic expression is an expression in which context is necessary to fully shape the meaning of that expression. This expression alone, without context, is semantically insufficient to achieve Reference [15: 103]. Therefore, Levinson's observation that deixis is a fly in the ointment for those researchers who perceive language as a generative system objectively describing the world is plausible [15: 97].

Due to the role of context in explaining the phenomenon of deixis, it is undoubtedly a phenomenon from the sphere of pragmalinguistics. Despite the development of this discipline located on the border between linguistics and the philosophy of language, interpretation of the phenomenon of deixis is still difficult. Some scholars directly admit that "we are far from understanding its boundaries and have no adequate cross-linguistic typology of deictic expression" [15: 97].

Pragmalinguistic and philosophical analyses have yielded some solutions in the characteristics of deixis and deictic expressions. They have so far demonstrated that deictic expressions have attentive, intentional and subjective properties that are based on the inclusion of the content of these expressions in objective descriptions [15: 106]. They also have projection features. When it comes to attentive properties, those are about directing the attention of the addressee of an utterance to some feature of the spatio-temporal context or the presumption of earlier existence of this attention [15: 102]. In the case of deictic expressions, the feature of intentionality is understood as expressing clues as to the reference in a given environment, also textual, by the creator of a given utterance [15: 103]. The attribute of subjectivity is only manifested in some deictic expressions and means that there may be a discrepancy between the subject of a given sentence and the subject that formulates it [15: 106]. As for the projective properties of deictic expressions, they result from the fact that deictic expressions do not contain any significant descriptive content, so their reading can only be referential (and only thanks to the context), and not additionally attributive, i.e. associated with assignment of some features. As such, deictic expressions also remain transparent in terms of intension. In addition, they cannot be negated [15: 106]. 
This complex picture of properties of deictic expressions shows that despite the apparent ease of drafting and interpreting referrals with deictic indications, they can ultimately, due to their own attributes, pose many problems - to lawmakers in pursuit of understandability of texts of normative acts, and to all those who interpret these texts in obtaining linguistically unquestionable results of interpretation. This will become especially visible when discussing cases of the phenomenon occurring in texts of normative acts named by W.V.O. Quine as "deferred ostension" [26: 195], which occurs when what is indicated by a deictic expression turns out to be something different than what it refers to [15: 105]. To show and explain this problem, it was proposed to distinguish the referring function of demonstratives [19: 156], which was supposed to answer the question of what manages the determination of the relation between the demonstrative and its reference when the listener receives an utterance containing a deictic expression. However, the use of the referring function of demonstratives did not solve all difficulties with the phenomenon of deferred ostension because still relatively little is known, for example, about the type of relation between the place of indication (demonstratum) and the place of reference (referent) that must occur in order for deferred ostension to appear [18: 161-163].

As for types of deixis, several of them have been distinguished in pragmaticspersonal, temporal, spatial, discursive and social [15: 112-121]. In deictic systemic referrals contained in texts of normative acts only one is used-discursive deixis. That is why some light should be shed on the concept of discursive deixis. Discursive deixis has similarities to temporal and spatial deixis. It is similar to the first one because it indicates the relation of the relevant segment of the utterance to the temporal positioning of the moment when the utterance appears or the moment when the utterance is received [15: 118-119]. Discursive deixis is similar to spatial deixis due to reference made to a part of discourse where such a reference can be interpreted only by determining where, i.e. in which fragment of the text, the current place of expression or current point of its reading or writing is located [15: 119]. It should be added that the phenomenon of deferred ostension may also occur in discursive deixis [34: 131-133].

Since discursive deixis is related to discourse in its space-time dimension, it is also associated with text, because text is always incomplete and indefinite in relation to the discourse that can be derived from the text by means of context [2: 999]. ${ }^{3}$ To put it simply, it can be assumed that discourse can be a product of a text. Taking this under consideration, it can even be said that deictic expressions in a text-due to the indispensability of context for understanding a given deixis-make the fragment of this text which contains the deictic expression more discursive, even when the context is understood, following Studnicki, Łachwa, Fall and Stabrawa, relatively narrowly, i.e. only as the sum of the textual surroundings and textual vicinity of a given fragment of text [30: 38]. It should be added here that, according to the authors of the aforementioned work, the textual surroundings of fragment $\mathrm{F}$ of text $\mathrm{T}$ is a set whose elements are text $\mathrm{T}$ and all specific fragments of text $\mathrm{T}$ to which fragment $\mathrm{F}$ is subordinated, while the textual vicinity of fragment $\mathrm{F}$ of text $\mathrm{T}$ is a set of text $\mathrm{T}$

\footnotetext{
${ }^{3}$ See also: [35: 8] and [12: 13].
} 
fragments which are non-identical with this fragment $\mathrm{F}$ and subordinated directly to the same fragment of higher order to which fragment $F$ is directly subordinated [30: 37]. A fragment of text is the part of the text distinguishable by means of formal criteria, not smaller than a sentence in a grammatical sense [30: 19]. ${ }^{4}$

The above characteristics of discursive deixis are complemented by an observation that it has an intratextual character [15:107]. This means, firstly, that its reference may concern only the part of a text in which the deictic expression responsible for the creation of such a deixis appears, and secondly, that transtextual references will be excluded from the scope of considerations. The discrepancy between the later mentioned conceptual grid of textual relations characteristic for texts of normative acts and references present therein and intratextuality of deictic expressions should be explained here in such a way that intratextuality of deictic expressions applies to both intratextual relations in texts of normative acts and intertextual relations occurring between texts of normative acts or their fragments. Intratextuality of deictic expressions is therefore understood as intratextuality sensu largo.

The abovementioned "maximum" reference range of a deictic expression, limited to the text in which it was found, is in line with the understanding of deictic indication by Studnicki, Łachwa, Fall and Stabrawa already pointed out at the end of part 2 of this article. According to them, if we are dealing with a referring phrase, which RARP gives the address of a specific fragment of the text, it should be assumed that it is a fragment located in the same source text in which the said phrase occurs [30: 111]. The authors add that the information enabling identification of the reference fragment is then derived from two sources, and neither of them can be omitted, because neither of these sources considered separately provides enough information to identify this fragment. These sources include the wording of the phrase in question and the fact that this phrase is located in a specific source text [30: 111].

It is not, however, that the identification of the referent and demonstratum of a deictic expression appearing as part of the referring phrase in the text of a normative act, as well as the possibility of assessing the compatibility of referent and demonstratum of such an expression, is based solely on two types of sources provided by Studnicki, Łachwa, Fall and Stabrawa. Even supplementing a given fragment of text with context understood as the sum of textual surroundings and textual vicinity, which is indispensable for deixis, will not be enough. It turns out that in the concept of the cited authors, for the legislatively correct use and understanding of a deictic referring phrase, it is necessary to take into account-although belonging

\footnotetext{
${ }^{4}$ Fragments of text can belong to different orders and be hierarchical, as well as enter into subordination relations. This is present in the case of texts of normative acts. In Poland, according to the Annex to the [24], hereinafter referred to as: "PLT", two macro-orders of fragments of text (systematic units as superior and editorial units as lower in position compared to systematic units) have been adopted. In Codes, systematic units (in order from the highest rank in the hierarchy) are Parts, Books, Titles, Divisions, Chapters, Subchapters (the last ones are optional), and editorial units (in the same order) are Articles and Paragraphs. Sentences are not specified in PLT, although there is no doubt in theory and practice that both Articles and Paragraphs may consist of sentences in the grammatical sense, which are fragments of a lower order compared to Articles and Paragraphs in the understanding of Studnicki, Łachwa, Fall and Stabrawa.
} 
to the legal discourse, but derived from outside the texts of all applicable normative acts-an additional factor, which they call the interpretative directive. In the case of all, and therefore also deictic, expressions contained in referring phrases in texts of normative acts, it boils down to the following statement: "The smallest of the hierarchically ordered fragments in which the content indicated by a given referring phrase is located will be treated as a fragment, which is a reference fragment for this phrase, while the smallest of the fragments ordered in the same way in which a given referring phrase is located will be called a source fragment for this phrase" [30: 36]. In other words, if, for example, a systematic unit of a text of a normative act, like a chapter, contains a referring provision drafted using the deictic referring phrase "the following provisions shall not apply", then according to the cited directive - not expressed in this or in any other text of the normative act- the reference to the given referring phrase "ends" with provisions following the provision containing the analysed referring phrase, but only those contained in the same chapter as the referring phrase, despite the fact that the indication of this referring phrase "ends" only at the last article of the text of the same normative act, probably located within the structure of the act, far from the provision containing the referring phrase in question. On the one hand, such a directive can be acclaimed as the basis for deliberate creation of a controlled, potential ${ }^{5}$ phenomenon of deferred ostension, but on the other hand, because of its existence, it is difficult to understand referring phrases, because supplementary to syntactic, semantic and contextual issues, an additional discursive factor must be taken into account, moreover, not the only one, because other similar directives may accompany referring phrases with indications other than the deictic indication.

As for the last of the strands mentioned at the beginning of part 3 of the article (various relations and conceptual traditions in which deixis is sometimes embedded and considered), it is too extensive and nuanced to be fully presented in this study. It is justified to merely indicate two frequently appearing doubts and to arrange necessary philosophical and linguistic excursions to dispel them.

The first doubt is the relation between the terms "indexicality" and "deixis", which is presented in such a way that the terms deixis and indexicality reflect different traditions associated with linguistic and philosophical approaches respectively [15: 97]. Following Nunberg, it is possible to say simply that linguists sometimes use the word "deictic" in more or less the same way in which language philosophers use the word "indexical" [20: 2].

The second issue that needs to be signalled and reported is the relation between deixis and anaphora. According to Cornish, deixis is prototypically used to draw the attention of the addressee to a new discourse object (or a new aspect of an existing object), which is implicitly derived from the situational context of expressionwhose focal point is "here and now" of verbal and non-verbal activity of the speaker. Anaphora is a procedure for referring to discourse, aimed at continuing the current

\footnotetext{
${ }^{5}$ Potential, because it is possible that such a referring phrase will appear in the last Chapter of a given text of a normative act, which will end in the same fragment of the text as any other superior fragment above it.
} 
focus of attention, established so far (or established hypothetically). Anaphoric reference means that referents of indexical expressions are presupposed by the speaker to obtain psychological significance or a level of focus on the side of the addressee of the speech in the place of the text in which they appear [2: 999]. According to Cornish, anaphora, both phylogenetically and ontogenetically, is a derivative of deixis, which itself is a source of Reference [2: 1000]. This priority and peculiar superiority of deixis to anaphora is evident when one sees that many deictic expressions can be used non-deictically_anaphorically, as in the sentence "We went to Verdi's Requiem last weekend and really enjoyed that" or non-anaphorically, as in "Last weekend we just did this and that" [15: 111]. It also often happens that a given anaphora is so closely associated with a deixis that they cannot be separated [15: 103], because it is not uncommon for an expression to be both anaphoric and deictic in character, which was reflected in the proposal to specify the phenomenon of "anadexis" and the "anadeictic expression" articulating it [3: 757ff.]. Some expressions used anaphorically, such as personal pronouns (in English, but also Polish), are referring expressions of general purpose-there is nothing inherently anaphorical about them and they can be used deictically or non-deictically (exoforically), such as in the phrase "He died" said about a colleague who, from the context of the discourse or situation, was known to be in a critical condition [15: 119]. Deixis and anaphora are also connected by the fact that both phenomena are classified as demonstratives [15: 108, figure 5.1]. Without being deeply involved in the issues of philosophy of language, for the purposes of these reflections it can be assumed that deixis will not be distinguished from anaphora, ${ }^{6}$ since a firm distinction between anaphorical expressions, which are components of referring phrases in texts of normative acts, and deictic expressions with the same function would require strong assumptions about referents presupposed by the legislator (as a speaker using these expressions). Each such assumption causes additional complications of editorial and interpretative operations carried out on utterances contained in texts of normative acts, and as a result lowers comprehensibility of the latter.

The above remarks can be considered an announcement of numerous difficulties related to the creation and interpretation of referring phrases. Part 7 of this study has been devoted to an attempt to capture and organize them.

\section{The State of Research on Comprehensibility of Texts of Normative Acts}

It would be a truism to briefly state that texts of normative acts are difficult to understand. However, such an appraisal is already formulated at the level of language analysis carried out in research based on methods that do not take into account obstacles specific to legal language. This is about an analysis of syntactic issues in the narrow sense (e.g. degree of sentence complexity), frequency issues (e.g. frequency of

\footnotetext{
${ }^{6}$ However, the difference between the cataphoric and anaphoric interaction of deictic expressions will be presented.
} 
occurrence of individual words in a sentence) and quantitative issues (e.g. number of words in a sentence or number of syllables in a word). So far many of such analyses have been conducted on texts of normative acts. ${ }^{7}$ One of them was made using the so-called FOG index. As stated by Malinowski, "(t)he FOG index (Jasnopis version) was used to assess readability of Polish Codes, the average, non-existent model Polish Code is characterized by an average readability FOG index $=12.78$ " $[17: 9] .{ }^{8}$ This is the level of readability ${ }^{9}$ defined as quite difficult, understandable to undergraduate students [17: 8-9], and thus far from the level expected for Codes whose addressees are not only students. After resigning from averaging, it turns out that the "simplest" existing Polish Code, i.e. the Penal Code, has the FOG readability index of 10.5, which means the level of language understood by high school students, and the "most difficult" Code according to the criteria of measuring the FOG index is the Executive Penal Code with the score of 15.1, which is equivalent to achieving a level of difficult language comprehensible to MA students [16: 27-28].

When taking into account the specificity of legal language difficulties in understanding texts of all normative acts containing legal provisions are highlighted. As Malinowski aptly observes, “(i)n» general-language «readability measures, individual normative acts are treated as autonomous objects, not semantically and functionally related to other acts of the legal system. The systemic and functional context of an examined utterance in legal language is not measured, as the methodology developed by linguists does not include this specific legal understanding of text" [17: 7]. The problem not covered by linguists in studies on comprehensibility of texts of normative acts is also the levelness of these texts [28, 29]. It results in the fact that "(r) eception of a legal text at the level of provisions is potentially possible for every user of the Polish language. However, this is not the proper reception of this text. Appropriate-adequate due to the genre of the text-is the normative level that is not perceptible prima facie" [1:236]. As a result, research conducted by linguists and the tools developed by them focus only on the properties of the represented surface layer of texts of normative acts (descriptive level, i.e. the level of legal provisions) and bypass problems with understanding the deep layer of these texts (normative level, i.e. the level of legal norms) [1: 240]. It should be added here that measurability of the factors mentioned here that reduce comprehensibility of texts of normative acts is a much greater challenge than in the case of parameters of interest to linguists such as sentence length or word length.

Texts of normative acts are also characterized by properties that, while remaining specific to this group of texts, at the same time affect the level of comprehensibility and can be included in the formula which is a model. It is about the occurrence of (1) intratextual relations, i.e. occurring within individual provisions, (2) intertextual relations occurring between provisions within individual texts of normative

\footnotetext{
7 Review of formulas, measures, indexes resulting from these analyses was carried out in the work of Malinowski [17: 7-11].

${ }^{8}$ For more information on the FOG index and Jasnopis program see: [10].

${ }^{9}$ Readability is understood here as a certain feature of a text concerning only its structure and wording. Its meaning is therefore narrower than the features of comprehensibility.
} 
acts, and (3) transtextual relations, which are links between provisions of individual texts of normative acts, groups of such provisions, entire texts of normative acts and their groups [4: 175ff.]. Such relations are shaped primarily by referrals expressed by referring phrases contained in referring provisions.

\section{The Impact of Referring Provisions on Comprehensibility of Texts of Normative Acts}

Referrals belong to the means of legislative technique and are therefore admissible in newly created or amended texts of normative acts. In Poland, based on the applicable Paragraphs 156-160 PLT, the premise for the legislator to use a referring phrase is the need to achieve brevity of this text or to ensure coherence of legal institutions regulated in it. Despite their advantages in terms of condensing and harmonizing the structure of texts of normative acts, referrals reduce their readability. As Malinowski notes, "(f)rom the point of view of readability, a referral creates difficulty in reading, because the fragment of the same or another text indicated in the referral should be identified, found, understood and associated with the content of the normative sentence in which the referral is located" [17: 11]. Part of this problem can be solved by hypertextualizing texts of normative acts [4: 269-275], which causes the interpreter-thanks to the adoption of a specific document structure and the support of appropriate IT tools- to "see" the correct segment of the text to which the referral is made without the need to look for it or associate it. ${ }^{10}$ However, actions aimed at understanding the textual compound created by referral remain the domain of the interpreter. Slightly ahead of the course of this reasoning, it should be added here that these compounds sometimes turn out to be interpretively demanding, despite the legislator using relatively simple words or expressions to communicate the functor and the argument of the referring phrase. Difficulties in interpretation of referring phrases, i.e. grasping what was indicated by the referring phrase and to what the reference was made, increase when one of the components of the referring phrase has imperfections that may have different origin.

Having the above in mind, it can be assumed for the purposes of further discussion that the text of a normative act will be considered understandable if it is possible to conduct a legal interpretation of it limited to linguistic manner in the scope necessary for the case being interpreted without any disruption deriving from this text (with full knowledge that a linguistic legal interpretation in many cases will not be sufficient to reproduce an unambiguous norm of behaviour). Consequently, the text of a normative act that contains linguistic, logical, structural or content defects which make linguistic legal interpretation difficult in this respect will be classified as incomprehensible. Defects of all these types also include errors as a subclass of defects of a given type, because it is assumed here that not every defect - as opposed

\footnotetext{
${ }^{10}$ An example of a record of a referral in the form of a structured text (XML) adopted in the scheme developed when creating the editor of legal acts (EDAP) ordered for the needs of the Ministry of the Interior and Administration is presented by Cyrul et al. [5: 110].
} 
to an error-results from acting contrary to the rule, and that the rules do not cover all linguistic behaviours and structural and content dependencies. ${ }^{11}$ Referring phrases are particularly significant from the point of view of comprehensibility of texts of normative acts or its lack due to relations with linguistic, logical, structural and content issues.

\section{Justification for the Choice of Codes as Sources of Examples}

The choice of Codes as the subject of analyses presented in part 7 of the article and the source for the selection of examples illustrating the considerations conducted therein is justified by the significance of the content of the Codes, a wide range of addressees and, as a consequence of both of these features of Codes, an increased expectation as to comprehensibility of the latter. Referring to the findings of Malinowski, this expectation can be reinforced by the expected particularly careful edition of Codes, as well as results of an analysis of existing Polish Codes, which show that the basic editorial units in Codes are on average half as short as in other acts [16: 25]. This author at the same time argues, based on the work of Świdziński [31], that "(t)he average length of sentences in the text, next to the frequency of difficult words, has a decisive impact on the values of linguistic measures of readability" [16: 26]. It should also be added that the length of Codes-from a few hundred to over a thousand articles-makes such normative acts particularly abundant in provisions referring to the wording of another, sometimes very distant in location, fragment of the same text in which the referring provision is placed. Therefore, since this study deals with deictic referrals, in the context of the above observation, searching for them in Codes gives hope for greater efficiency in finding and in a higher number of such referrals. In addition, the persistence of Polish Codes, understood as their long validity since the initial promulgation (including amendments made in various, also in terms of political system, and temporarily distant periods), is a hypothetical announcement of the multitude of types of deictic referrals, and this is because of the ways in which legislative drafters have been editing the referring phrases that have changed over the years. These methods, as not directly shaped by Polish principles of legislative technique, may-in particular in relation to the argument of a referring phrase in a deictic referral — be part of the individual style of a given legislative drafter. Despite such expectations and many special properties and functions of Codes in the legal system, texts of Polish Codes remain, as shown in part 4, difficult to understand. Therefore, examples of Code referring provisions with a deictic indication should be the subject of further analysis.

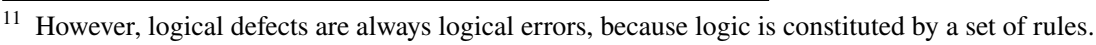




\section{Drafting and Interpretative Challenges Identified in the Analysis of Examples of Deictic Referrals in the Codes}

Problems arising in connection with the formulation of legal referring phrases with deictic indications can be divided into external (E) and internal (I). The external ones will include difficulties the essence of which does not relate to the phenomenon of deixis and its complexity. This group, therefore, will contain problems regarding (E1) the inability to find and qualify deictic referrals by using solely the morphology and syntax of a given RARP, (E2) increased requirements for editorial aspects of legislative drafting related to the provisions being the subject of reference or indication of a given deictic expression, as well as (E3) the consequences of lack of uniformity of the conceptual grid adopted by the legislator during the creation of various provisions with deictic indications. Cases in which the object of indication of ARP differs from the object of reference of the same ARP (I1) will be perceived as internal troubles. This subset will also include problems related to (I2) ambiguity of ARP caused by incorrect RSP or lack of RSP. All these problems are discussed further in the order listed above along with appropriately selected examples taken from Polish Codes and-where possible - suggestions on how to avoid a given difficulty in drafting newly created referring provisions with deictic indication.

The E1 problem can be illustrated by the following example:

Art. $505^{15} \S 2$ of the Code of Civil Procedure [21], hereinafter referred to as: "CCP"

In the case examined in accordance with the provisions of this chapter, the provisions on other separate proceedings shall not apply.

The assumption made in the system of automated resolution of referrals with deictic indications that the syntactic identification of an expression is sufficient to characterize the type of indication, in this case would cause this system to mistakenly assign not only the demonstratum of the deictic expression, but also the referent of that expression. In the analysed case, the legislator did not use one referring phrase with a deictic indication, which reads "the provisions of this chapter shall not apply", but two referring phrases.

$(2 \mathrm{~b})$

Art. $505^{15} \S 2 \mathrm{CCP}$

In the case examined [in accordance with the provisions of this chapter] $]_{1}$ [the provisions on other separate proceedings shall not apply $]_{2}$.

Square brackets were used to show both referring phrases, the first of which is a phrase with a deictic indication, and the second with a semantic indication, i.e. indicating a reference fragment by characterizing its content [30: 49] by means of a specific RSP of RARP atom. This case exemplifies accuracy of the thesis that formal analysis, including the creation of a catalogue of referring phrases with deictic indications, is insufficient to resolve deictic referrals in texts of normative acts. 
The E2 problem is in fact a confirmation of the above observation, although it emerges from the point of view of not only resolving referrals, but making legislative interference in the content of the textual surroundings of a fragment of a text of a normative act containing a referring phrase with a deictic indication.

(3)

\section{Art. 956 CCP}

If the enforcement concerns one or more pieces of real estate located in different judicial districts, the announcement shall be made public in all competent courts.

Art. 957 CCP

(Repealed)

\section{Art. 958 CCP}

$\S 1$. At the time of the announcement of the auction of real estate belonging to a farm, a co-owner of this real estate, who is not a personal debtor, shall have the right to take ownership of the property up to the third day before the auction at a price not lower than the sum of the estimate. When applying for takeover, the applicant should submit a deposit, unless the law releases them from it.

$\S 2$. If several co-owners submit an application for takeover, priority is given to the one who runs a farm or works in it. If this condition is met by several coowners or none of them, the court will give priority to this co-owner who gives the best guarantee of due running of the farm.

\section{Art. 959 CCP}

The court decides on the priority of taking over real estate pursuant to the two preceding articles by issuing a bid adjudication decision.

The citation of four Articles in example (3) was needed to demonstrate the problem that arose in Article 959 at the time of legislative action consisting in repealing Article 957. The RARP in Article 959 indicates "the two preceding articles", i.e. Article 957 and Article 958, in accordance with the presented systematics of the text of a normative act. The demonstratum of the deictic expression "the two preceding articles" contained in Article 959 are therefore Article 957 and Article 958, and more precisely their content, which cannot be empty, i.e. emptied of normative content. Meanwhile, the referent of the same expression is currently empty, because Article 957 does not contain any content that may be a reference of ARP contained in Article 959. Therefore, a problem of deferred ostension arose, which was not originally present in RARP of the deictic referral in Article 959. ${ }^{12}$ Only because the editorial unit "Art. $X$ " is not traditionally removed from the text of a normative act

\footnotetext{
12 As a side note, it may be wondered whether the problem of deferred ostension accompanies every referral in the text of a normative act in whose RARP the name of the editorial unit or its abbreviation appears. This strand was discussed in: [30: 22-23].
} 
as a result of repealing provision $X$, there is no reason to claim that de lege lata the demonstratum and the referent of the deictic expression "the two preceding articles" in Article 959 became, next to Article 958, the provision of Article 956. De lege ferenda it is only possible to recommend to the legislator a more careful analysis of textual surroundings when making legislative operations in the text of a normative act containing a referring phrase with a deictic indication, which in relation to the above example is also recommended by scholars and commentators of Polish civil law [9].

The most complex of the external problems is problem E3, concerning the effects of the lack of uniformity of the conceptual grid adopted during the creation of various provisions with deictic indication. Its presentation should begin with the following example:

(4)

Art. $557 \mathrm{CC}$

$\S 1$. The seller is released from liability under implied warranty for defects, if the buyer knew about the defect at the time the contract was concluded.

$\S 2$. If the object of the sale is fungibles or things which are to be created in the future, the seller is released from liability under implied warranty for defects if the buyer knew about the defect at the time of delivery of the item. This provision shall not apply when the buyer is a consumer.

$\S 3$. The seller is not liable to the buyer who is a consumer for the fact that the item sold does not have the properties resulting from public assurances referred to in Art. $556^{1} \S 2$, if these assurances were not known or, judging reasonably, could not have been known or they could not influence the buyer's decision to conclude a sales contract, or if their content was corrected before the conclusion of the sales contract.

The subject of interest here is a referring phrase with a deictic indication "this provision shall not apply" located in Article 557, Paragraph 2, sentence 2. In RARP there is an R-macrostandard 13 "provision" and RSP "this". The R-macrostandard provides problems in terms of referral resolution. It should be known what understanding of the word "provision" was assumed during the drafting of the entire content of Article 557. Assuming that the entire content included in the editorial unit of the Article is the "provision", the demonstratum and the referent of the deictic expression "this provision" is the entire content of Article 557 preceding the content of Article 557, Paragraph 2, sentence 2 (i.e. Article 557, Paragraph 1 and Article 557, Paragraph 2, sentence 1), as well as the entire content of Article 557 following the content of Article 557, Paragraph 2, sentence 2 (and therefore also Article 557, Paragraph 3). In this case it should be considered that the pronoun "this" used as

\footnotetext{
13 The macrostandard is a component of the semantic structure of referring phrases, corresponding to the word "provision" appearing in their surface structure, used to designate a fragment of a text not specified as to its type. The R-macrostandard is a component of the surface structure of the referring phrase corresponding to the macrostandard occurring in the semantic structure [30: 112].
} 
RSP works both anaphorically (backwards) and cataphorically (forwards). ${ }^{14}$ Assuming that the "provision" means all the content of an editorial unit of an order lower than an Article, which is a Paragraph, and in ordinary Acts a Section (if the Article is divided into such editorial units), due to the use of the singular form of the word "provision", the scope of indication and reference of the referring phrase "this provision shall not apply" is limited to the content of Article 557, Paragraph 2, sentence 1 , so the pronoun "this" has anaphoric impact. On the other hand, assuming the narrowest understanding of the "provision" does not change anything as to the scope of indication and reference of the referring phrase in question, of course, as long as it is considered that the pronoun "this" anaphorically indicates the preceding sentence in relation to the sentence in which it occurred (and creates a reference to this preceding sentence), i.e., it is synonymous with the adjective "preceding" or "above". Therefore, differences in the way of understanding the R-macrostandard "provision" also influence the shaping of the meaning of RSP "this" and, ultimately, the possibility of the occurrence of the problem of deferred ostension. The conceptual intricacies occurring in the described example increase after becoming acquainted with the following examples, which more clearly demonstrate de lege lata the accuracy of the remark that "a large number of sentences in one Article or Section should be avoided, because then there are problems with interpretation of the mutual relation between individual sentences" [36: 374].

(5)

Art. 316 CC

A pledgee may claim satisfaction from a pledged thing regardless of any limitation on the debtor's liability under inheritance law

Art. 317 CC

The limitation period for a claim secured by a lien does not affect the pledgee's right to obtain satisfaction from the encumbered thing. The above provision shall not apply to claims for interest or other accessory performances.

The subject of interest here is the referring phrase with the deictic indication "the above provision shall not apply" located in the content marked as Article 317, sentence 2. Similar to example (4), example (5) also requires knowledge about the legislator conceptual grid, on the basis of which it will be possible to identify the demonstratum and the referent of the deictic expression "the above provision". This is related to the question arising during the analysis of the last example, whether a single sentence within an editorial unit such as an Article (or a Paragraph, and in an ordinary Act a Section) is a legal provision, or is it all the content marked with the editorial unit of an Article and, optionally, a Paragraph (a Section in an ordinary Act). Without such knowledge or having no access to it, the interpreter will not be sure whether the deictic expression "the above provision" found in RARP in Article 317, sentence 2 indicates the content marked as Article 317, sentence 1 and creates a reference to this content or to the content of the entire Article 316. Before answering

${ }^{14}$ On the difference between cataphoric and anaphoric use of expressions in discourse: [30: 28], [33: 33], [15: 108 and 119]. 
this question, it is worth looking at another example-because, although the importance of the problem associated with this answer could be reduced prima facie and de lege ferenda by using editorial units of an order lower than Articles (and Paragraphs or, in ordinary Acts, Sections) and labelling all content currently included in Article 317, sentence 2 as Paragraph 2 (with the simultaneous transformation of the label of the current content of Article 317, sentence 1 into Article 317, Paragraph 1), this solution, while minimizing one problem, could generate another. This is illustrated by the example below.

(6)

Art. $791 \mathrm{CC}$

$\S 1$. Payment of the amounts due to the carrier and acceptance of the shipment without stipulations extinguish all claims against the carrier under the carriage contract. This does not apply, however, to claims related to invisible damage to a shipment if, within a week of accepting the shipment, the consignee notifies the carrier about the damage.

$\S 2$. The above provision shall not apply if the damage is due to the wilful misconduct or gross negligence of the carrier.

With reference to the same subject of investigation as in example (5), when considering example (6) a question arises whether the referring phrase with the deictic indication of "the above provision shall not apply" contained in Article 791, Paragraph 2 refers to all content included in Article 791, Paragraph 1, or only to the content included in Article 791, Paragraph 1, sentence 2. What is crucial in this example, as in example (5), is the adoption of a specific convention as to the understanding of what a legal provision is, and the determination within that convention of the status of editorial units in defining what a legal provision is.

If the provision is considered to be a sentence in a grammatical sense (from dot to dot or from dot to semicolon, or from semicolon to dot) [41: 17], ${ }^{15}$ then the referring phrase contained in Article 791, Paragraph 2 refers only (in terms of both demonstratum and referent) to the content of Article 791, Paragraph 1, sentence $2,{ }^{16}$ and therefore differently to the understanding of the range of this referring phrase adopted by many commentators of Article 791 representing the Polish thought of civil law [13, 27, 39]. Moreover, the adoption of such a convention also means that in example (5) the referring phrase contained in Article 317, sentence 2 refers to the first sentence in the same Article.

\footnotetext{
15 Zieliński adds that usually such a sentence is highlighted in the text and marked as an Article, Paragraph or Section.

16 This is due to the fact that with a given method of understanding the provision, only the content of Article 791, Paragraph 1, sentence 2 corresponds to the meaning contained in RARP of Article 791, Paragraph 2 of the deictic expression "the above provision", which relates at the same time to a provision located in the text above and only to one provision.
} 
However, if a different convention-according to which the provision is the entire content of a given Article, or Paragraph, and in ordinary Acts of a Section ${ }^{17}$-is adopted, inconsistency arising from the views of Polish civil law scholars and commentators appears. Acceptance of such a convention would necessitate the recognition that in example (6) the referring phrase in Article 791, Paragraph 2 refers to the entire content of Article 791, Paragraph 1, i.e. in accordance with the views of the quoted commentators of Article 791, but would also mean that it would be necessary to recognize that in example (5) the referring phrase in Article 317, sentence 2 refers to the entire content of Article 316, despite statements of other commentators included in the collections of comments edited by the same authors [11, 32, 40]. Therefore, as clearly indicated, some conventional decisions at the definition level of "provision" and "sentence" seem indispensable to resolve referrals with deictic indications.

The analysis of examples (5) and (6) may also raise a de lege lata doubt referring to the supposition of a hypothetical legislative technique adopted in the Civil Code, assuming the lack of use of the word "sentence" when formulating referrals with a deictic indication and replacing it with the word "provision". Such a technique could partly defend the view about the accuracy of adopting the first of the semantic conventions of the word "provision" discussed above, according to which the provision is not only the entire content of a given Article, Paragraph or, in an ordinary Act, Section, but also individual sentences in the grammatical sense found in these editorial units. However, currently in the Civil Code there are six appearances of the word "sentence" - in various inflected forms - in the role of RST. Therefore, it is difficult to conclude that the technique of referring to individual sentences has not been applied in the Civil Code, which clearly illustrates, for example, the RARP deictic phrase "preceding sentence" appearing in Article 815, Paragraph 3, sentence 2 CC:

\section{Art. $815 \mathrm{CC}$}

$\S 1$. The policyholder is obliged to inform the insurer of all circumstances known to it, which the insurer asked in the offer form or in other letters before contract conclusion. If the policyholder concludes the contract through a representative, this obligation also rests with the representative and also covers the circumstances known to the representative. If the insurer concludes the insurance contract despite receiving no reply to particular enquiries, the omitted circumstances are deemed insignificant.

\section{$\S 2$. If the insurance contract stipulates that during its duration, any change in the circumstances referred to in the preceding paragraph should be reported, the policyholder is obliged to notify the insurer of those changes immediately on learning of them. This provision shall not apply to life insurance.}

\footnotetext{
17 In example (6), unlike example (4), and similar to example (5), the meaning of "provision" as the entire content of the Article was excluded from the subject of discussion. This is caused by a terminological decision emerging - in the Polish case-from the content of Paragraph 55, Section 1 PLT in connection with Paragraph 55, Section 3 PLT, which requires considering both an Article and a Paragraph (Section in the ordinary Act) as an independent "provision".
} 
$\S 2^{1}$. If the insurance contract is concluded on another person's account, the obligations set forth in the preceding paragraphs rest on the policyholder and the insured, unless the insured did not know about the conclusion of the contract on his account.

$\S 3$. The insurer shall not be liable for the consequences of circumstances which, in violation of the preceding paragraphs, have not been communicated to him. If the violation of the preceding paragraphs occurred due to wilful misconduct, in case of doubt it is assumed that the event provided for in the contract and its consequences are the result of the circumstances referred to in the preceding sentence.

An example in which the legislator makes a referral of the same type as in examples (5) and (6), but without a doubt as to the accepted convention concerning the meaning of the "provision" (used in the plural), is found in Article 218, Paragraph 2 of CC:

Art. $218 \mathrm{CC}$

$\S 1$. Co-owners who did not receive an agricultural farm or its part but who resided on the farm until the co-ownership was cancelled retain the right to continue residing on the farm, though no longer than five years and if they are minors at the time the co-ownership is cancelled no longer than five years after attaining majority. The limitation of the term does not apply to co-owners who are permanently unable to work.

$\S 2$. Provisions on the easements of habitation shall apply accordingly to the rights arising from the provisions of the preceding paragraph.

It is clearly seen here that "provisions" mean individual sentences in the grammatical sense contained in Article 218, Paragraph 1 as constituents of this Paragraph.

An expression of similar clarity as to the semantic convention of the "provision" (used in the plural) was given in the content of Article 431, Paragraph 2 CC:

Art. $431 \mathrm{CC}$

$\S 1$. Anyone who keeps or uses an animal is obliged to remedy any damage the animal causes irrespective of whether it was under his supervision, or had strayed or run away, unless neither he nor a person for whom he is responsible is at fault.

$\S 2$. Even if a person who keeps or uses an animal is not responsible for it in accordance with the provisions of the preceding paragraph, the aggrieved party may demand full or partial remedy of damage from him if it follows from the circumstances, and especially from a comparison of the financial condition of the aggrieved party and that of that person, that the principles of community life so require. 
However, in Article 431, Paragraph 2 the word "provisions" was used incorrectly (and as non-R-macrostandard), ${ }^{18}$ because Paragraph 1 of this Article consists of only one sentence in a grammatical sense. The legislator should have kept the singular form and should have used the word "provision", while the whole RARP should be given the form of the "provision of the preceding paragraph", or even a more concise form of the "preceding paragraph".

Further problems with deictic expressions in referring phrases are described as internal. The ones previously marked as I1 will be discussed first. Their analysis can be initiated by presenting the following example:

Art. $817 \mathrm{CC}$

$\S 1$. The insurer is obliged to make the performance within thirty days of being notified about the event.

$\S 2$. If it is not possible to clarify the circumstances necessary to determine the insurer's liability or the amount of the performance within the above period, the performance should be made within 14 days from the day on which, with due diligence, it was possible to clarify these circumstances. However, the undisputed part of the performance should be made by the insurer within the period set forth in $\S 1$.

$\S 3$. An insurance contract or general terms and conditions of insurance may contain provisions more favourable for the entitled party than those specified in the preceding paragraphs.

Unlike example (3), in which the phenomenon of deferred ostension arose by the use of neglectful legislative technique, and unlike in examples (4), (5) and (6), where the problem of deferred ostension could arise due to the adoption of one of several possible meanings of the "provision" R-macrostandard, in example (10) the occurrence of deferred ostension is not associated with either RST or the R-macrostandard of the referring phrase, but with RSP. In example (10) there is not the slightest doubt as to what is understood by RST "paragraphs", as well as what the demonstratum and referent of RST itself is. The problem arises because of RSP "preceding" that accompanies RST "paragraphs". The demonstratum of RSP "preceding" in the deictic expression "preceding paragraphs" is undoubtedly all the provisions included in the Paragraphs which in the text of a given normative act precedes RST "paragraphs" contained in Article 817, Paragraph 3. However, a doubt arises in the case of an attempt to assume that the referent is the same. This doubt is generated by the context. It can be dispelled with the following arguments. First of all, due to the wording of the entire Article 817, Paragraph 3, this should only concern the preceding Paragraphs that in some way relate to the insurance contract or terms and conditions of insurance (a contextual argument from the content of the referring provision in which the deictic

\footnotetext{
18 The word "provisions" is unnecessary here, as its removal in the case of accompanying RST (in the analysed Article 431, Paragraph 2 CC the role of RST is played by the "paragraph") does not cause any changes in the meaning of the referring phrase-cf. [30: 113].
} 
expression is found). Secondly, as far as the deictic expression in the Civil Code is concerned, it is in no way likely that the entire Civil Code applies only to the insurance contract or terms and conditions of insurance (a contextual argument from the title and type of normative act in which the deictic expression is found). Thirdly, if it is noted that the referring provision in which the deictic expression in question appears is marked as Paragraph 3 in Article 817, it is unlikely that all the Paragraphs included in all previous 816 Articles-assuming that no provisions have been added to or removed from this set of provisions-concerned the insurance contract or terms and conditions of insurance (a contextual argument from the place of referring provision in which the deictic expression is found in the structure of the text of a normative act).

Taking this into account, it does not seem that the view on the identity of the demonstratum and the referent of the deictic expression "preceding sections" in Article 817, Paragraph 3 of the Civil Code can be defended. Therefore, the phenomenon of deferred ostension occurs on the basis of the analysis of the context of the deictic expression. Its presence is taken into account and "approved" by the interpretative directive, which has already been mentioned, requiring the interpreter to treat as the reference fragment only the smallest among the hierarchically ordered fragments of a given text, in which the content indicated by a given referring phrase is located. In the example in question, this fragment is Article $817 \mathrm{CC}$.

It should be added to the above that the phenomenon of deferred ostension can be observed in the referring provisions in the texts of normative acts also in the case of a discrepancy in the genre of the object of indication and the object of reference of a given deictic expression articulating RARP. This occurs, for example, in the referring phrases which read "the above rules apply" or "the above restrictions do not apply". In this study, however, they are not analysed, because they are referring phrases with a semaphoric indication [30: 48-49], which is, respectively, blank [30: 128-130] and substantive [30: 130-131].

Among the problems identified as internal, there are also those related to the ambiguity of ARP caused by incorrect RSP or lack of RSP in RARP (I2). Attention was paid to them during the analysis of the structure of the text of the Polish Penal Code [25: 246-247], giving the following examples:

Art. 8 of the Penal Code [23], hereinafter referred to as: "PC".

A felony can only be committed intentionally; a misdemeanour can also be committed unintentionally if the Act so provides.

Art. $10 \S 1$ PC

$\S 1$. The principles set out in this Code concern persons who commit a prohibited act at or after the age of 17 .

Art. 11 PC

$\S 1$. The same act may constitute only one crime. 
$\S 2$. If an act meets the legal definition of a crime specified in two or more provisions of the Penal Act, the court shall convict for one crime on the basis of all converging provisions.

$\S 3$. In the case referred to in $\S 2$, the court shall impose a penalty on the basis of a provision providing for the strictest penalty, which shall not preclude adjudication of other measures provided for in the Act on the basis of all converging provisions.

When analysing the graphically highlighted RARP, it is possible to see that a deictic expression occurs in example (11), which has been drafted solely by means of RST "Act" without any RSP. In the more elaborate example (12), the RST "Code" appears, which is narrower in meaning than the "Act", ${ }^{19}$ together with the pronoun RSP "this", while the most complex is the deictic expression appearing in example (13). It consists of RST "Act" and RSP "Penal", and also of the word "provisions", which does not appear in the role of R-macrostandard, and terms referring to the number of provisions ("two or more").

In accordance with the stipulation made that both components of the RA of the referring phrase (RST and RSP) must appear in the part of the text corresponding to the expression of reference, example (11) raises doubts as to which act is in question. Adopting a slightly modified version of the said interpretative directive ordering to refer to the smallest of the hierarchically ordered fragments of a given text, only the Penal Code can be the reference fragment of the word "Act" in the referring phrase from example (11). However, there seems to be no grounds to assent that RARP includes a deictic expression ${ }^{20}$ _ because RARP lacks RSP. In example (11), without the support of the interpretative directive, and thus without the context being extended, neither the demonstratum is expressed nor the referent is articulated. Extending the context here would bear a risk of a serious misunderstanding, as it is argued in the legal thought of Polish penal law that referring to the "Act" in example (11) does not apply only to the text of the normative act in which the referring phrase "if the Act so provides" occurs, but also to penal provisions contained in other acts [25: 247], e.g. the Act on counteracting drug addiction or the Act on safety of mass events. It is therefore clear that relying on an "extratextual" context for determining the referent of a referring phrase may prove to be fallible. This remark also applies to example (13), in which the adjective clarification that it is about a "Penal Act" does not eliminate the doubts as to the text of which act the reference is made.

The above-described difficulties concerning the interpretation of referrals in examples (11) and (13) do not apply to example (12). There is no doubt here as to the deictic nature of the expression "this Code" and as to the determination of demonstratum and referent of that expression. Despite this, such a referral occurs less frequently [25: 247] in the Polish Penal Code than referrals such as in examples (11) and (13).

19 In the Polish legal system, every Code is an Act, but not every Act is a Code.

${ }^{20}$ Przetak considers likewise [25: 247]. 


\section{Summary}

It will not be an exaggeration to say that deictic expressions in referring phrases are "referrals in referrals". Prima facie, especially for a non-professional interpreter, referring phrases with deictic indications seem to be the simplest to interpret, i.e. the most understandable referrals. Ultimately, however, with a sufficiently careful and in-depth interpretation, they reveal many difficulties, which neither the legislator nor the interpretative "tools" provided by the legislator, such as, for example, the Polish PLT, help to solve in any way.

Bearing in mind the above observations made in this study, in order to dispel doubts arising in connection with deictic referrals, it is of course always possible to use interpretative directives from outside the text of a given normative act, ${ }^{21}$ but it is much better to make an effort to understand the existing structure of referrals and to work out an improved version of it on this basis, which will not require-at least in relation to the texts of new or amended normative acts-the use of extratextual interpretative directives when drafting referrals or during classical legal interpretation, or will require it less often. On the other hand, knowledge of certain semantic conventions, which cannot be derived directly from the text of a given normative act, and therefore does not belong to the context of a given referring phrase, should constitute a permanent component of the reasoning system used to draft referrals with deictic indication, as well as the intellectual equipment of every interpreter who wants to understand the text of a given normative act.

It should be remembered that any maintenance of the assumption about the presupposed referents of deictic expressions and the adoption of certain interpretative directives not incorporated into the text of a normative act limits in this scope the possibility of algorithmizing legislative and interpretive operations performed on the text of a normative act. In addition, such operations, when performed neglectfully, without sufficient insight, can give false hope for the identity of demonstratum and referent of a given deictic expression. As the presented examples have shown, texts of Polish Codes contain many fragments with deferred ostension, as well as fragments where even many professional interpreters may have difficulties in indicating the range of reference.

Despite the high degree of precision in the considerations and usability of the proposed conceptual grid-including the typology of referring phrases_of Studnicki, Fall, Łachwa and Stabrawa, it is impossible to agree with their statement, according to which " $(. .$.$) the function of referring phrases creating loose encirclements is not$ about indicating directly a relevant content to the user, but only about highlighting such areas of the database in which further searches may take place" [30: 19]. If the functions of referrals indicated in the Polish PLT are accepted, i.e. shortening or harmonizing the text of a normative act, the deictic referrals which, despite the incorporated promise to indicate a specific location in the text of a normative act,

\footnotetext{
21 An example of the use of such a directive in the jurisprudence of the Polish Constitutional Tribunal to determine the relation between two sentences included in the content marked with one given editorial unit is presented in: [36: 374].
} 
leave ambiguity or uncertainty as to the scope of the indication, can satisfy neither the legislator nor the interpreter. This argument is strengthened when considering the case of discrepancies between the relatively clear demonstratum and the referent of the deictic expression constituting the R-argument of the referring phrase with deictic indication, which are expressed by this referring phrase.

In addition to the aforementioned drawbacks of deictic referrals, i.e. the need to use a special interpretative directive and difficulties caused by the deferred ostension phenomenon that may accompany deixis, it is also necessary to point out a drawback in the form of a strong connection between deictic referrals and information on the division of the text of a normative act that is important when resolving such referring phrases [30: 113]. In the event of an incorrect division of the text of a normative act or indication of an incorrect fragment by the legislator, the deictic referral will not direct the interpreter's attention to the correct referent and will not fulfil its function as such. An additional problem with deictic referrals may also be the accumulation of chain deictic referrals, i.e. occurring in a situation where provisions containing a deictic referral refer to provisions that also refer deictically. The possible use of such a referral technique-although erroneous from the perspective of Paragraph 157 PLT, which prohibits all cascading referrals, but appearing in practice-will pose a challenge of interpretation as a kind of abuse of deictic referrals in the structure of the text of a normative act, and will result in poor comprehensibility of this text in the scope of the referring provisions.

If one is tempted to make detailed recommendations regarding deictic referrals in the texts of normative acts, it should be admitted that it might be useful to consider specifying the role of "sentences" as fragments of the text of a normative act which is the subject of a wider interest of theoreticians of law-making and sets of guidelines in the field of drafting normative text. The current regulation of the Polish set of such guidelines is rather restrained in relation to the issue of "sentences", 22 which, as shown in the example of deictic referrals, in which the "sentence" appears as RST, raises interpretation difficulties. In addition, in the current state of the set of drafting and interpretative directives adopted in Poland, the R-macrostandard "provision" should be used in deictic referrals with extreme caution, especially when it occurs in the plural.

The general conclusion, after analysing deictic referrals in texts of normative acts of Polish Codes, would be the observation that the drafting of referring provisions with a deictic indication requires very high precision and perseverance in maintaining a coherent and uniform systematics of the text of a normative act. It is also necessary to maintain absolute consistency in applying conventions concerning the meaning of the words appearing in the referring phrase as RST or as RSP, as these conventions cannot be omitted when interpreting referring provisions, despite the ultimately contextual determination of the referral of the deictic expression that is part of the referring phrase in the referring provision.

\footnotetext{
${ }^{22}$ Currently only a few Paragraphs PLT-Paragraph 7, Paragraph 55, Section 2-4, Paragraph 59, Section 2 and Paragraph 67, Section 2-concern "sentences".
} 
Funding This publication is a result of the research Project No. UMO-2018/29/B/HS5/01433 entitled "Legislative errors and the comprehensibility of legal texts" funded by the National Science Centre (Poland) and carried out at the Faculty of Law and Administration of the Jagiellonian University in Cracow (Poland).

\section{Compliance with ethical standards}

Conflict of interest Not applicable.

Code availability Not applicable.

Open Access This article is licensed under a Creative Commons Attribution 4.0 International License, which permits use, sharing, adaptation, distribution and reproduction in any medium or format, as long as you give appropriate credit to the original author(s) and the source, provide a link to the Creative Commons licence, and indicate if changes were made. The images or other third party material in this article are included in the article's Creative Commons licence, unless indicated otherwise in a credit line to the material. If material is not included in the article's Creative Commons licence and your intended use is not permitted by statutory regulation or exceeds the permitted use, you will need to obtain permission directly from the copyright holder. To view a copy of this licence, visit http://creativecommons.org/licen ses/by/4.0/.

\section{References}

1. Choduń, Agnieszka. 2018. Postulat jasności prawa. Plain language czy praca edukacyjna [Requirement of Clarity for Law. Plain Language or Legal Education]. Krytyka prawa [Critique of Law] 3: 226-244.

2. Cornish, Francis. 2008. How indexicals function in texts: Discourse, text, and one neo-Gricean account of indexical reference. Journal of Pragmatics 40: 997-1018.

3. Cornish, Francis. 2011. 'Strict' anadeixis, discourse deixis and text structuring. Language Sciences 33: 753-767.

4. Cyrul, Wojciech. 2012. Wptyw procesów komunikacyjncych na praktykę tworzenia $i$ stosowania prawa [Impact of Communication Processes on the Practice of Creating and Applying Law]. Warsaw: Wolters Kluwer business.

5. Cyrul, Wojciech, Jerzy Duda, Janusz Opiła, and Tomasz Pełech-Pilichowski. 2014. Informatyzacja tekstu prawa [Computerization of the Text of Law]. Warsaw: Wolters Kluwer Business.

6. de Maat, Emile, Radboud Winkels, and Tom van Engers. 2006. Automated detection of reference structures in law. In Proceedings of the 2006 conference on Legal Knowledge and Information Systems: JURIX 2006: The Nineteenth Annual Conference, ed. Tom van Engers, 41-50. Amsterdam: IOS Press.

7. Francesconi, Enrico. 2014. A description logic framework for advanced accessing and reasoning over normative provisions. Artificial Intelligence and Law 22: 291-311.

8. Francesconi, Enrico, and Andrea Passerini. 2007. Automatic classification of provisions in legislative texts. Artificial Intelligence and Law 15: 1-17.

9. Gil, Piotr. 2020. Komentarz do art. 959, teza 2 [Commentary on Art. 959, thesis 2]. In Kodeks postępowania cywilnego. Komentarz [The Code of Civil Procedure. Commentary], ed. Elwira Marszałkowska-Krześ. Legalis: C.H. Beck.

10. Gruszczyński, Włodzimierz, and Maciej Ogrodniczuk (eds.). 2015. Jasnopis, czyli mierzenie zrozumiałości polskich tekstów użytkowych [Jasnopis, i.e. Measuring the Comprehensibility of Polish Non-literary Texts]. Warsaw: Wydawnictwo ASPRA-JR.

11. Grzesiok-Horosz, Agnieszka. 2019. Komentarz do art. 317, teza 1 [Commentary on Art. 317, thesis 1]. In Kodeks cywilny. Komentarz [The Civil Code. Commentary], ed. Mariusz Załucki. Legalis: C.H. Beck. 
12. Jaszczolt, Katarzyna M. 2005. Default semantics foundations of a compositional theory of acts of communication. Oxford: Oxford University Press.

13. Konert, Anna. 2019. Komentarz do art. 791, teza I.2 [Commentary on Art. 791, thesis I.2]. In Kodeks cywilny. Komentarz [The Civil Code. Commentary], ed. Mariusz Załucki. Legalis: C.H. Beck.

14. Levinson, Stephen C. 1983. Pragmatics. Cambridge: Cambridge University Press.

15. Levinson, Stephen C. 2006. Deixis. In The handbook of pragmatics, ed. Laurence R. Horn and Gregory Ward, 97-121. Malden-Oxford-Carlton: Blackwell Publishing.

16. Malinowski, Andrzej. 2016. Komunikatywność polskich kodeksów [The Communicativeness of Polish Codes]. Zeszyty Naukowe Sadownictwa Administracyjnego [Scientific Journals of Administrative Judiciary] 1: 24-33.

17. Malinowski, Andrzej. 2017. Pomiar czytelności polskiego tekstu prawnego [Measuring the Readability of the Polish Legal Text]. Państwo i Prawo [State and Law] 5: 3-18.

18. Mount, Allyson. 2008. Intentions, gestures, and salience in ordinary and deferred demonstrative reference. Mind and Language 23 (2): 145-164.

19. Nunberg, Geoffrey. 1979. The non-uniqueness of semantic solutions: Polysemy. Linguistics and Philosophy 3 (2): 143-184.

20. Nunberg, Geoffrey. 1993. Indexicality and deixis. Linguistics and Philosophy 16: 1-43.

21. Polish Act of 17 November 1964 - the Code of Civil Procedure (Consolidated text: Journal of Laws of 2019, item 1460, as amended).

22. Polish Act of 23 April 1964-The Civil Code (Consolidated text: Journal of Laws of 2019, item 1145, as amended).

23. Polish Act of 6 June 1997-the Penal Code (Consolidated text: Journal of Laws of 2019, item 1950, as amended).

24. Polish Ordinance of the Prime Minister of 20 June 2002 on "The Principles of Legislative Technique" (Consolidated text: Journal of Laws of 2016, item 283).

25. Przetak, Marzena. 2015. Struktura tekstu prawnego na przykładzie kodeksu karnego [Structure of the Legal Text on the Example of the Penal Code]. Gdańsk: Wydawnictwo Uniwersytetu Gdańskiego.

26. Quine, Willard V.O. 1968. Ontological Relativity. Journal of Philosophy 65 (7): 185-212.

27. Raczyński, Aleksander. 2019. Komentarz do art. 791, teza 2 [Commentary on Art. 791, thesis 2]. In Kodeks cywilny. Tom III. Komentarz. Art. 627-1088 [The Civil Code. Vol. III. Commentary on Art. 627-1088], ed. M. Gutowski. Legalis: C.H. Beck.

28. Sarkowicz, Ryszard. 1995. Levels of interpretation of a legal text. Ratio Juris 8 (1): 104-112.

29. Sarkowicz, Ryszard. 1995. Poziomowa interpretacja tekstu prawnego [Level Interpretation of the Legal Text]. Cracow: Wydawnictwo Uniwersytetu Jagiellońskiego.

30. Studnicki, Franciszek, Andrzej Łachwa, Jarosław Fall, and Ewa Stabrawa. 1990. Odesłania w tekstach prawnych. Ku metodom ich zautomatyzowanej interpretacji [Cross-references in Statutory Texts. Towards the Methods of their Automated Interpretation]. Zeszyty Naukowe Uniwersytetu Jagiellońskiego (seria M). Prace prawnicze [Scientific Papers of the Jagiellonian University (the M Series). Juridical works] 136: 1-201.

31. Świdziński, Marek. 1996. Własności składniowe wypowiedników polskich [Syntactic Properties of Polish Sentential Combinations]. Warsaw: Dom Wydawniczy Elipsa.

32. Szadkowski, Karol. 2018. Komentarz do art. 317, teza 1 [Commentary on Art. 317, thesis 1]. In Kodeks cywilny. Tom I. Komentarz do art. 1-352 [The Civil Code. Vol. 1. Commentary on Art. 1-352], ed. M. Gutowski. Legalis: C.H. Beck.

33. Tran, Oanh Thi, Bach Xuan Ngo, Minh Le Nguyen, and Akira Shimazu. 2014. Automated reference resolution in legal texts. Artificial Intelligence and Law 22: 29-60.

34. Webber, Bonnie Lynn. 1991. Structure and ostension in the interpretation of discourse deixis. Language and Cognitive Processes 6 (2): 107-135.

35. Widdowson, Henry G. 2004. Text, context, pretext. Critical issues in discourse analysis. Oxford: Blackwell Publishing.

36. Wierczyński, Grzegorz. 2016. Redagowanie i ogłaszanie aktów normatywnych. Komentarz [Drafting and Promulgation of Normative Acts. Commentary]. Warsaw: Wolters Kluwer.

37. Wyner, Adam. 2015. From the language of legislation to executable logic programs. In Logic in the theory and practice of lawmaking, ed. Michał Araszkiewicz and Krzysztof Płeszka. Cham: Springer.

38. Yule, George. 1996. Pragmatics. Oxford: Oxford University Press. 
39. Zbiegień-Turzańska, Anna. 2020. Komentarz do art. 791, teza II.4 [Commentary on Art. 791, thesis II.4]. In Kodeks cywilny. Komentarz [The Civil Code. Commentary], ed. K. Osajda. Legalis: C.H. Beck.

40. Żelechowski, Łukasz. 2020. Komentarz do art. 317, teza 1 [Commentary on Art. 317, thesis 1]. In Kodeks cywilny. Komentarz [The Civil Code. Commentary], ed. K. Osajda. Legalis: C.H. Beck.

41. Zieliński, Maciej. 2017. Wykładnia prawa. Zasady, reguły, wskazówki [Legal Interpretation of Law. Warsaw: Wolters Kluwer.

Publisher's Note Springer Nature remains neutral with regard to jurisdictional claims in published maps and institutional affiliations. 